\title{
Theoretical and Experimental Studies on the Adsorption of N- [(E)-Pyridin-2-ylmethylidene] Aniline, a Schiff Base, on Mild Steel Surface in Acid Media
}

\author{
Mohanapriya. $\mathrm{N}^{1,2}$, Kumaravel. $\mathrm{M}^{2 *}$, and Lalithamani. $\mathrm{B}^{1}$ \\ ${ }^{1}$ Department of Chemistry, Sri Ramakrishna Engineering College, Coimbatore 641 022, Tamilnadu, India \\ ${ }^{2}$ Department of Chemistry, PSG College of Technology, Coimbatore 641 004, Tamilnadu, India
}

\begin{abstract}
The adsorption of N-[(E)-Pyridin-2-ylmethylidene] aniline, a Schiff base, on to mild steel surface in $1 \mathrm{M} \mathrm{HCl}$ and $0.5 \mathrm{M}$ $\mathrm{H}_{2} \mathrm{SO}_{4}$ solutions and the consequent corrosion protection were studied employing weight loss method, electrochemical impedance spectroscopy and potentiodynamic polarization measurements. DFT calculations were performed to investigate its interaction with the metal surface at the atomic level to understand its inhibition mechanism. The adsorption process is well described by the Langmuir isotherm. The thermodynamic parameters indicated that the adsorption is spontaneous and the interaction of the inhibitor at the mild steel surface is mainly through physisorption. The $\mathrm{R}_{\mathrm{a}}$ values obtained in AFM studies for the uninhibited and inhibited sample in $\mathrm{HCl}$ media respectively are 0.756 and $0.559 \mu \mathrm{m}$, and that in $\mathrm{H}_{2} \mathrm{SO}_{4}$ media are 0.411 and $0.406 \mu \mathrm{m}$. The lesser roughness values of the inhibited sample shows the adsorption of the molecules onto the mild surface. The inhibition efficiencies were found to improve with concentration of the inhibitor and the maximum efficiency was observed at 400ppm in all the investigation methods adopted. The inhibitor was found to exhibit a higher efficiency in $\mathrm{HCl}$ media $(95.7 \%)$ than in $\mathrm{H}_{2} \mathrm{SO}_{4}(92.8 \%)$. The theoretical and experimental results are found to be in good agreement.
\end{abstract}

Keywords : Corrosion, Inhibitor, Potential of Zero Charge, Atomic Force Microscopy, Density Functional Theory

Received : 12 July 2019, Accepted : 30 September 2019

\section{Introduction}

Iron, the most widely used metal in many industries, undergoes corrosion in mild as well as in aggressive environments. Various methods are available for corrosion control and the use of organic inhibitors is one amongst the most appropriate ways to achieve this objective $[1,2]$. The organic compounds containing polar functional groups with nitrogen, oxygen or sulphur atoms and conjugated system act as good corrosion inhibitors in acid media [3-7]. The inhibitive property of organic molecules depends on several factors such as structure and the charge distribution, the number and types of adsorption sites on the

*E-mail address: mkvteam.research@gmail.com

DOI: https://doi.org/10.33961/jecst.2019.00430

This is an open-access article distributed under the terms of the Creative Commons Attribution Non-Commercial License (http://creativecommons.org/licenses/by-nc/4.0) which permits unrestricted non-commercial use, distribution, and reproduction in an medium, provided the original work is properly cited. metal surface and the nature of interaction between them [8-10]. The inhibitive nature is attributed to the adsorption ability of the organic molecules on the corroding metal surface follows some known adsorption isotherms with respect to the reactive centres in the inhibitor resulted from polar functional groups. The resulting adsorbed film acts as a diffusion barrier for the aggressive environments [11]. The kinetics of the electrochemical reactions that constitute the corrosion processes are generally influenced by the metal-solution interface and thereby modify the metal dissolution in acid media by changing the structure of electrical double layer [12,13]. Investigations on corrosion inhibition of the organic molecules attained great attention, and various investigations have given series of reports proving that schiff bases could function as effective corrosion inhibitors [1416]. Apart from the requirements of the presence of an electron cloud on the aromatic ring, the synthesized Schiff base possess electronegative nitrogen 
atom and the presence of a $\mathrm{C}=\mathrm{N}$ group, all of them expected to facilitate greater adsorption of the compound onto the steel surface importing effective inhibition, the synthesis of the current Schiff base involved an easy synthetic route using low cost starting material [17]. Several industrial processes are carried out using acid solutions especially sulphuric and hydrochloric acids. Therefore in the present investigation the inhibition efficiency of the compound in $1 \mathrm{M} \mathrm{HCl}$ and $0.5 \mathrm{M} \mathrm{H}_{2} \mathrm{SO}_{4}$ have been studied and compared using weight loss method and electrochemical techniques such as Electrochemical impedance spectroscopy (EIS) and potentiodynamic polarization studies. The mechanism of inhibition is also discussed based on the Potential of Zero Charge (PZC) and adsorption isotherm. Quantum chemical calculations have also been performed to substantiate the experimental observations $[18,19]$.

\section{Experimental}

\subsection{Materials}

The mild steel specimen used for gravimetric study has the dimension of $2.5 \times 1 \times 0.1 \mathrm{~cm}$ with the elemental composition of $0.084 \% \mathrm{C}, 0.037 \% \mathrm{Mn}$, $0.026 \% \mathrm{P}, 0.021 \% \mathrm{~S}$ and the balance Fe. Emery sheets of different grades like 220, 400, 600, 800 and 1200 were used to polish the specimens mechanically and washed with double distilled water. The specimens were degreased with acetone and then dried. A Teflon coated cylindrical mild steel rod of exposed area $1 \mathrm{~cm}^{2}$ was used for electrochemical studies. All the solutions were prepared using double distilled water.

\subsection{Synthesis of Schiff base}

Equimolar mixture of Pyridine-2-carboxaldehyde and aniline in ethanol was stirred for 30 minutes at room temperature and the precipitated schiff base, $\mathrm{N}$ [(E)-Pyridin-2-ylmethylidene] aniline (PMA) was washed with ethanol and dried at room temperature. Purity of the schiff base was confirmed from the appearance of a single spot in TLC. The structure of the schiff base is shown in Fig. 1.

The disappearance of the characteristic peak for $\mathrm{C}$ $=\mathrm{O}$ at $1700 \mathrm{~cm}^{-1}$ and the appearance of a new peak at $1679 \mathrm{~cm}^{-1}$ for $\mathrm{C}=\mathrm{N}$ in the FTIR spectra confirmed the formation of the schiff base (Fig. 2).<smiles>C(=N/c1ccccc1)\c1ccccn1</smiles>

Fig. 1. Structure of the synthesized schiff base N-[(E)Pyridin-2-ylmethylidene] aniline (PMA).

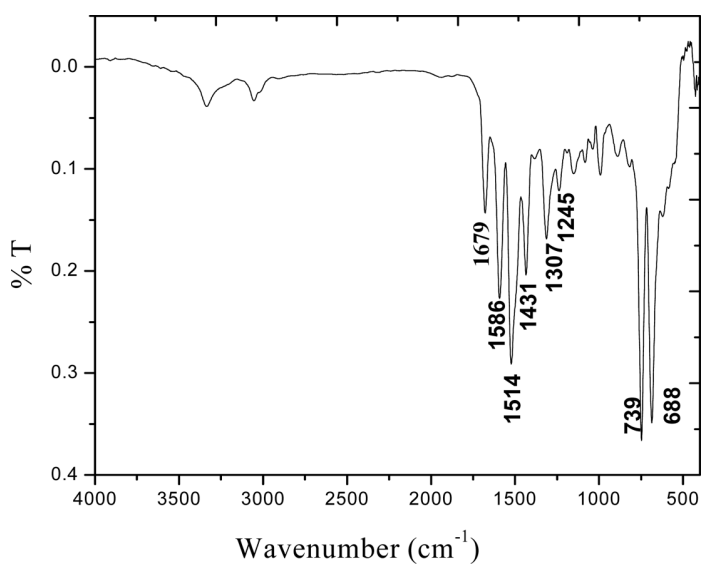

Fig. 2. IR spectrum of the schiff base (PMA).

\subsection{Weight loss measurements}

ASTM procedure was followed for weight loss measurements to quantify the rate of corrosion and inhibitor effectiveness [20]. The prepared mild steel samples in triplicate were completely immersed in $100 \mathrm{~mL}$ of $1 \mathrm{M} \mathrm{HCl}$ and $0.5 \mathrm{M} \mathrm{H}_{2} \mathrm{SO}_{4}$ solutions with different concentrations 10, 50, 100, 200, 300, 400, 500,600 and $700 \mathrm{ppm}$ ) of the inhibitor at $30 \pm 1^{\circ} \mathrm{C}$ for 2 hours and then washed, dried and weighed. The average of the weight loss was taken for corrosion rate calculations and the inhibitor efficiency was determined from the following relationship [21].

$$
\operatorname{IE}(\%)=\frac{\mathrm{W}_{\text {B.S. }}-\mathrm{W}_{\text {I.S. }}}{\mathrm{W}_{\text {B.S. }}} \times 100
$$

Where, IE is the inhibitor efficiency, $\mathrm{W}_{\text {B.s. }}$ is the weight loss in blank solution, $\mathrm{W}_{\text {I.S. }}$ is the weight loss in inhibited solution.

\subsection{Electrochemical Impedance measurements}

Electrochemical studies have been carried out using a Potentiostat/Galvanostat (Gamry Reference 
600). In the three electrode system, a teflon coated mild steel rod with an exposed area of $1 \mathrm{~cm}^{2}$ served as the working electrode, a saturated calomel electrode as the reference and a platinum mesh served as the counter electrode. The EIS measurement was performed in the frequency range from $10^{6}$ to $10^{-2} \mathrm{~Hz}$ at the open circuit potentials by imposing a sinusoidal AC perturbation of $10 \mathrm{mV}$, after immersion for 30 $\min$ in the acid media. The charge transfer resistance $\left(\mathrm{R}_{\mathrm{ct}}\right)$ values were used to determine the inhibition efficiencies as per the following relationship [22].

$$
\% \mathrm{IE}=\frac{\mathrm{R}_{\mathrm{ct}}{ }^{\prime}-\mathrm{R}_{\mathrm{ct}}}{\mathrm{R}_{\mathrm{ct}}{ }^{\prime}} \times 100
$$

Where $\mathrm{R}_{\mathrm{ct}}$ is the charge transfer resistance in the inhibited solution, $R_{c t}$ is the charge transfer resistance in the uninhibited solution. The reproducibility of the results was ensured by repeating the experiments for a minimum of 3 times and the average of the results obtained were used to calculate the inhibition efficiencies [23].

\subsection{Potentiodynamic polarization measurements}

The potentiodynamic polarization curves were recorded from a more negative potential than $E_{\text {ocp }}$ to a more positive potential than $E_{\text {ocp }}$ through $E_{\text {corr }}$ at a sweep rate of $1.67 \mathrm{mV} / \mathrm{s}$. The inhibition efficiencies were calculated using the equation (3) [24].

$$
\% \text { IE }=\frac{i_{\text {corr }}-i_{\text {corr }}{ }^{\prime}}{i_{\text {corr }}} \times 100
$$

Where $i_{\text {corr }}$ is the corrosion current density in uninhibited solution and i' ${ }_{\text {corr }}$ is the corrosion current density of inhibited solution.

\subsection{Potential of zero charge (PZC)}

The double layer capacitance $\left(\mathrm{C}_{\mathrm{dl}}\right)$ values were obtained from the impedance response of the corroding electrode at $100 \mathrm{~Hz}$ at an $\mathrm{AC}$ amplitude of $10 \mathrm{mV}$ at different applied DC potentials and PZC was determined by plotting the differential capacitance values against the applied DC potential.

Adsorption of the inhibitor on the metal surface mainly depends on the surface charge on the metal. The sign of $E_{r}$ can be found using the following formula (7) [25].

$$
E_{r}=E_{o c p}-E_{P Z C}
$$

Where,

$\mathrm{E}_{\mathrm{PZC}}=$ Potential of zero charge

$\mathrm{E}_{\mathrm{r}}=$ Antropov's rational corrosion potential

$\mathrm{E}_{\mathrm{OCP}}=$ Open circuit potential

\subsection{Surface analysis}

AFM surface morphological study was carried out as per the literature [26]. Freshly pre-treated mild steel coupons were immersed in the media $(1.0 \mathrm{M}$ $\mathrm{HCl}$ and $0.5 \mathrm{M} \mathrm{H}_{2} \mathrm{SO}_{4}$ ) in the absence and in the presence of the inhibitor. The specimens were retrieved after 3 hours, washed with distilled water and dried before subjecting to AFM analysis [27]. An Atomic Force Microscope (APE Research, Italy- A100) was used to image the sample's surface in contact mode at a scan area of $30 \mu \mathrm{m} \times 30 \mu \mathrm{m}$ at $5000 \mathrm{~nm} / \mathrm{s}$ scan rate. The Gwyddion 2.47 program was used for image processing.

\section{Results and Discussion}

\subsection{Weight loss method}

The corrosion inhibition efficiencies of the schiff base (PMA) for mild steel in both the acid media are shown in Table 1. Increase in inhibitor concentration increases its efficiency. When a mild steel surface is immersed in an acid solution containing an inhibitor, a portion of the surface gets covered, termed as surface coverage which is represented by $\theta$ [28]. Linear relationship between inhibitor concentration and $\theta$ is observed till the formation of completely covered surface, beyond which, addition of inhibitor has no influence [20,29].

Maximum inhibition efficiencies were found to be $80 \%$ and $76 \%$ respectively in $\mathrm{HCl}$ and $\mathrm{H}_{2} \mathrm{SO}_{4}$ medium at $400 \mathrm{ppm}$ of inhibitor and the difference in efficiencies with respect to acid is due to the influence of anion adsorption on the surface of the metal [30]. The specific adsorption of anions is expected to be more pronounced with anions having a smaller degree of hydration such as chloride ions $\left(\mathrm{Cl}^{-}\right)$. As they are being specifically adsorbed, they create an excess negative charge towards the solution phase and favour enhanced adsorption of the amine cations leading to an increased inhibition of corrosion [31]. Thus adsorption of organic molecules is not always directly on to the metal surface [32] but in some cases occurs through already adsorbed chloride or sulphate 
Table 1. Inhibitor efficiencies from weight loss measurement for mild steel in $1.0 \mathrm{M} \mathrm{HCl}$ and $0.5 \mathrm{M} \mathrm{H}_{2} \mathrm{SO}_{4}$ solutions in the presence and in the absence of the inhibitor.

\begin{tabular}{|c|c|c|c|c|}
\hline Medium & $\begin{array}{c}\text { Inhibitor } \\
\text { concentration }\end{array}$ & $\begin{array}{l}\text { Corrosion } \\
\text { rate } \\
(\mathrm{mpy})\end{array}$ & $\begin{array}{c}\text { Surface } \\
\text { coverage } \\
(\theta)\end{array}$ & $\% \mathrm{IE}$ \\
\hline \multirow{10}{*}{$1 \mathrm{M} \mathrm{HCl}$} & Blank & 1240 & - & - \\
\hline & 10 & 930 & 0.25 & 25 \\
\hline & 50 & 744 & 0.40 & 40 \\
\hline & 100 & 558 & 0.55 & 55 \\
\hline & 200 & 496 & 0.60 & 60 \\
\hline & 300 & 372 & 0.70 & 70 \\
\hline & 400 & 248 & 0.80 & 80 \\
\hline & 500 & 275 & 0.78 & 78 \\
\hline & 600 & 325 & 0.74 & 74 \\
\hline & 700 & 285 & 0.77 & 77 \\
\hline \multirow{10}{*}{$\begin{array}{c}0.5 \mathrm{M} \\
\mathrm{H}_{2} \mathrm{SO}_{4}\end{array}$} & Blank & 1425 & - & - \\
\hline & 10 & 1111.5 & 0.22 & 22 \\
\hline & 50 & 912 & 0.36 & 36 \\
\hline & 100 & 741 & 0.48 & 48 \\
\hline & 200 & 612.8 & 0.57 & 57 \\
\hline & 300 & 441.8 & 0.69 & 69 \\
\hline & 400 & 342 & 0.76 & 76 \\
\hline & 500 & 425 & 0.70 & 70 \\
\hline & 600 & 386 & 0.73 & 73 \\
\hline & 700 & 351 & 0.75 & 75 \\
\hline
\end{tabular}

ions at the interface. The lesser interference by sulphate ions might be the reason for the lower adsorption and the inhibition of corrosion [33]. Beyond $400 \mathrm{ppm}$, further increase in surface coverage with inhibitor concentration is marginal, showing that an optimum concentration has been reached (Fig. 3).

\subsection{EIS}

The EIS results were analysed using the equivalent circuit [-R (CR) -]. The Nyquist plot at various concentrations of the inhibitor showed single depressed capacitive semicircles and the diameter of the capacitive loop increased with increase in inhibitor concentration (Fig. 4), suggesting that inhibition of corrosion is achieved by controlling the charge transfer process [34]. In this equivalent circuit, $R_{s}$ is the solution resistance, $R_{c t}$ is the charge transfer resistance and CPE is

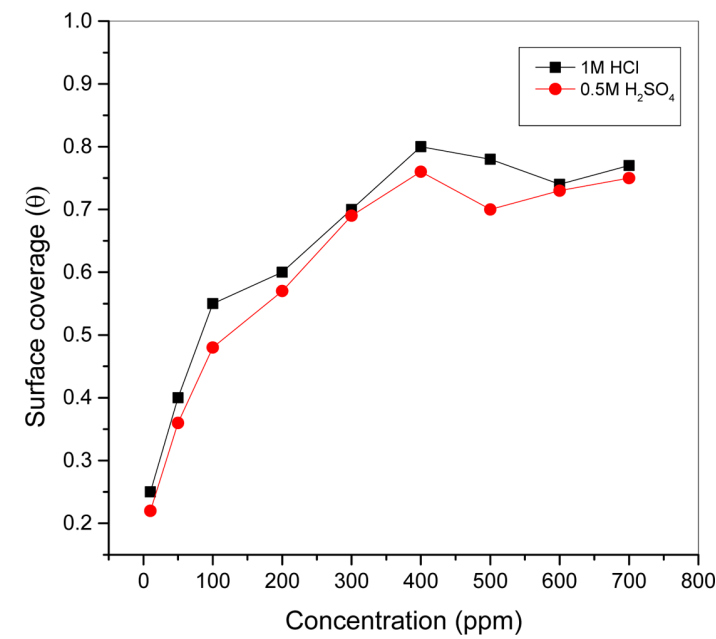

Fig. 3. Variation of surface coverage in the presence of different concentrations of PMA in $1 \mathrm{M} \mathrm{HCl}$ and $0.5 \mathrm{M}$ $\mathrm{H}_{2} \mathrm{SO}_{4}$ on mild steel after 2 hours immersion time.
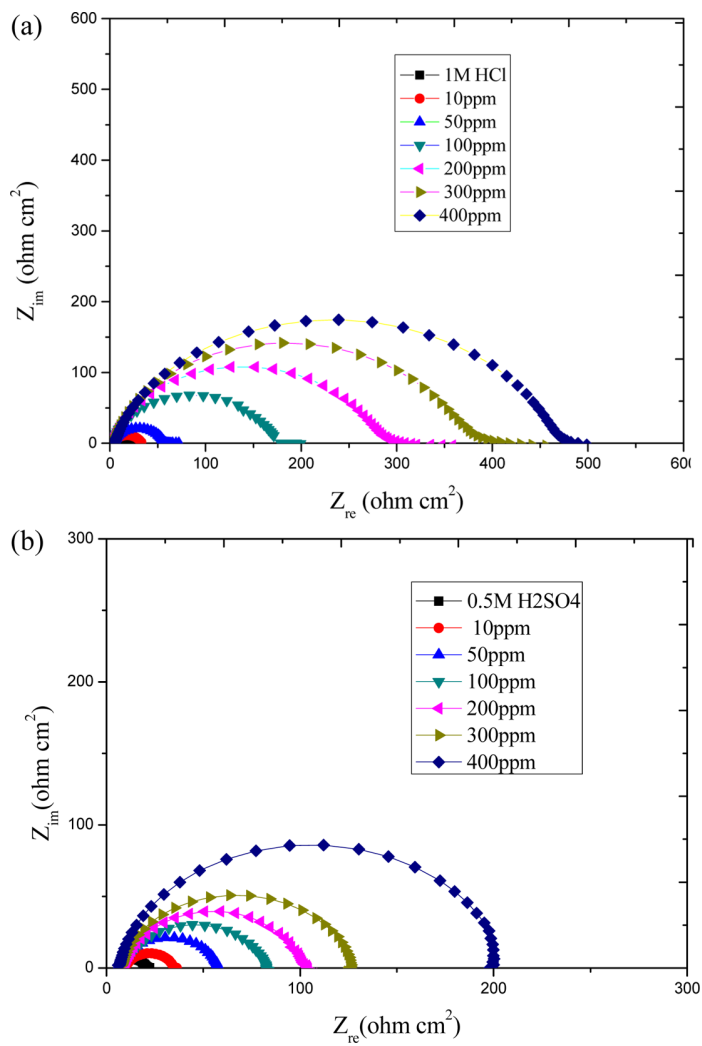

Fig. 4. (a) Nyquist plots for mild steel in $1 \mathrm{M} \mathrm{HCl}$ solution in absence and presence of various concentration of PMA (b) Nyquist plots for mild steel in $0.5 \mathrm{M} \mathrm{H}_{2} \mathrm{SO}_{4}$ solution in absence and presence of various concentration of PMA 
a constant phase element which is placed in parallel to the charge transfer resistance element. Thus, in this situation pure double layer capacitance $\left(\mathrm{C}_{\mathrm{dl}}\right)$ is better described by a transfer function with constant phase element to give a more accurate fit $[35,36]$.

$$
Z_{C P E}=Y_{0}^{-1}(j \omega)^{-n}
$$

Where,

$\mathrm{Y}_{0}$ is admittance of the corrosive system at $1 \mathrm{rad} \mathrm{s}^{-1}$ $\mathrm{n}$ is a constant $(-1 \leq \mathrm{n} \leq 1)$. While $\mathrm{n}=0$, the CPE represents a pure resistor, if $\mathrm{n}=+1$, it represents a pure capacitor and if $n=-1$, it represents an inductor [20]. $\omega$ is the angular frequency at which the imaginary part of the impedance is the maximum.

The capacitive loops have depressed semicircular appearance, $0.5 \leq \mathrm{n} \leq 1$, which is referred to as frequency dispersion as a result of the non-homogeneity [37,38] or the roughness [39] of the solid surface. The value of angular frequency can be calculated using the following expression [20].

$$
\omega=\left(\frac{1}{R_{c t} Y_{o}}\right)^{1 / n}
$$

The double layer capacitance, $\mathrm{C}_{\mathrm{dl}}$, for a circuit indicating a CPE is calculated from the following equa- tion $[40,36]$.

$$
C=Y_{o}\left(\omega_{n}^{\prime \prime}\right)^{n-1}
$$

As a result increased surface coverage $(\theta) R_{c t}$ values increase with increase in inhibitor concentration as evidence from Table 2 [41]. The decrease in local dielectric constant and / or an increase in the thickness of the electrical double layer is the cause for the decrease in $\mathrm{C}_{\mathrm{dl}}$ and $\mathrm{Y}_{\mathrm{o}}$ values with increase in the inhibitor concentration, which might also be due to the gradual replacement of water molecules by the organic molecules on the metal surface [42]. Slightly higher IE values is observed in EIS studies, when

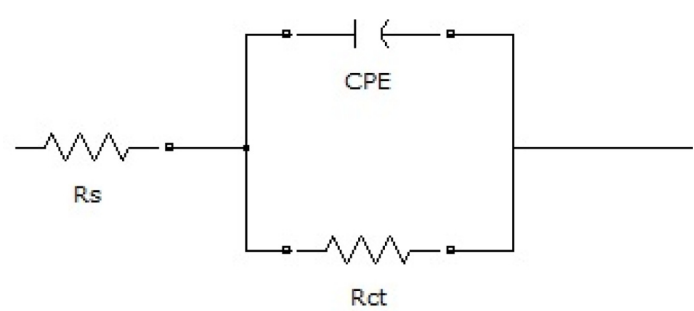

Fig. 5. Equivalent circuit for the mild steel surface / corrosive media interface with CPE.

Table 2. Electrochemical impedance parameters obtained for the corrosion of mild steel in $1.0 \mathrm{M} \mathrm{HCl}$ and $0.5 \mathrm{M} \mathrm{H}_{2} \mathrm{SO}_{4}$ solutions at different concentrations of the inhibitor.

\begin{tabular}{ccccccccc}
\hline \hline S. No & Medium & $\begin{array}{c}\text { Concentration } \\
(\mathrm{ppm})\end{array}$ & $\mathrm{R}_{\mathrm{ct}}\left(\Omega \mathrm{cm}^{2}\right)$ & $\begin{array}{c}\mathrm{Y}_{0} \\
\left(\times 10^{-6} \Omega^{-1} \mathrm{~cm}^{-2}\right)\end{array}$ & $\mathrm{n}\left(\times 10^{-3}\right)$ & $\mathrm{C}_{\mathrm{dl}}\left(\mu \mathrm{Fcm}^{-2}\right)$ & $\begin{array}{c}\text { Surface } \\
\text { coverage }(\theta)\end{array}$ & $\% \mathrm{IE}$ \\
\hline 1 & & $\mathrm{Blank}$ & 19.90 & 80.08 & 862.8 & 20.10 & - & - \\
2 & 10 & 29.25 & 75.24 & 835.2 & 13.68 & 0.319 & 31.9 \\
3 & & 50 & 52.46 & 71.57 & 870.3 & 7.63 & 0.621 & 62.1 \\
4 & $\mathrm{HCl}$ & 100 & 165.6 & 60.63 & 885.2 & 2.42 & 0.879 & 87.9 \\
5 & & 200 & 280.6 & 50.35 & 840.2 & 1.43 & 0.929 & 92.9 \\
6 & & 300 & 370.6 & 45.02 & 840.5 & 1.08 & 0.946 & 94.6 \\
7 & & 400 & 465.8 & 41.27 & 822.8 & 0.86 & 0.957 & 95.7 \\
\hline 8 & & $\mathrm{Blank}$ & 14.01 & 110.2 & 868.0 & 22.48 & - & - \\
9 & 10 & 25.45 & 98.93 & 860.7 & 12.38 & 0.449 & 44.9 \\
10 & & 50 & 50.99 & 90.64 & 878.0 & 6.18 & 0.725 & 72.5 \\
11 & $\mathrm{H}_{2} \mathrm{SO}_{4}$ & 100 & 73.96 & 81.52 & 862.4 & 4.26 & 0.811 & 81.1 \\
12 & & 200 & 93.78 & 76.65 & 894.9 & 3.36 & 0.851 & 85.1 \\
13 & & 300 & 119.8 & 70.40 & 889.6 & 2.63 & 0.883 & 88.3 \\
14 & & 400 & 195.8 & 64.80 & 923.1 & 1.61 & 0.928 & 92.8 \\
\hline
\end{tabular}


compared to that of weight loss measurement and the efficiencies were found to be $95.7 \%$ and $92.8 \%$ at 400ppm inhibitor concentration in $\mathrm{HCl}$ and $\mathrm{H}_{2} \mathrm{SO}_{4}$ media respectively. The result confirms that the inhibitive performance of the schiff base (PMA) is better in $\mathrm{HCl}$ rather than in $\mathrm{H}_{2} \mathrm{SO}_{4}$ medium.

\subsection{Potentiodynamic polarization measurements}

Representative polarization curves for the corrosion of mild steel in the acids with different concentrations of the inhibitor are respectively presented in Fig.6. The associated electrochemical parameters namely, corrosion potential $\left(\mathrm{E}_{\mathrm{corr}}\right)$, corrosion current density $\left(i_{\text {corr }}\right)$, Tafel slopes $\left(\beta_{\mathrm{a}}, \beta_{\mathrm{c}}\right)$, corrosion rate $(\mathrm{CR})$ and the calculated inhibition efficiencies are presented in Table 3. From these results, it is observed that, upon increasing the inhibitor concentration, the corrosion current density decreases and the inhibitor efficiency increases. The addition of the inhibitor affects the anodic mild steel dissolution as well as the cathodic hydrogen evolution reactions as it is evident from the shifts in $\beta_{\mathrm{a}}$ and $\beta_{\mathrm{c}}$ values. This implies that PMA is a mixed type inhibitor [43].

In general, a compound is considered to be anodic or cathodic type when the shift in $\mathrm{E}_{\text {corr }}$ is greater than $85 \mathrm{mV}$; otherwise, it is a mixed type [44]. However,
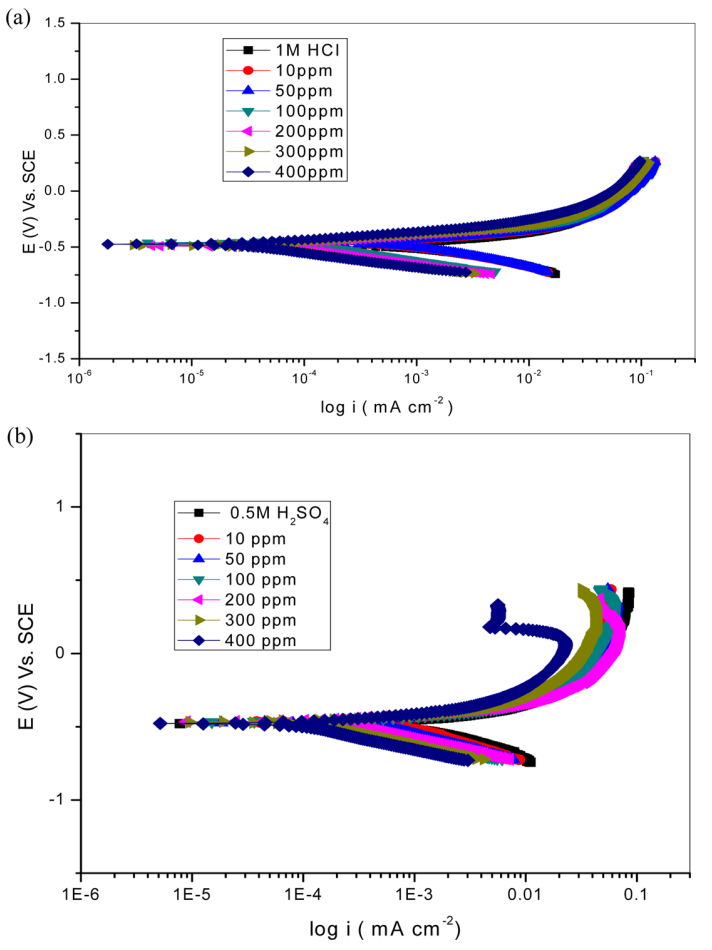

Fig. 6. Tafel plots for the corrosion of mild steel in (a) $1 \mathrm{M}$ $\mathrm{HCl}$ solution at various concentration of PMA (b) $0.5 \mathrm{M}$ $\mathrm{H}_{2} \mathrm{SO}_{4}$ solution at various concentration of PMA.

Table 3. Electrochemical polarization parameters recorded during corrosion of mild steel in $1.0 \mathrm{M} \mathrm{HCl}$ and $0.5 \mathrm{M} \mathrm{H}_{2} \mathrm{SO}_{4}$ at various concentrations of the inhibitor.

\begin{tabular}{cccccccc}
\hline \hline S. No & Medium & $\begin{array}{c}\text { Concentration } \\
(\mathrm{ppm})\end{array}$ & $\beta \mathrm{a} \mathrm{mV} / \mathrm{dec}$ & $\beta \mathrm{c} \mathrm{mV} / \mathrm{dec}$ & $\left.\mathrm{I}_{\text {corr }}(\mu \mathrm{A} \mathrm{cm})^{-2}\right)$ & $\mathrm{E}_{\text {corr }}(\mathrm{mV} / \mathrm{SCE})$ & $\% \mathrm{IE}$ \\
\hline 1 & & Blank & 174.8 & 252.0 & 1690 & -487.0 & - \\
2 & 10 & 150.5 & 248.1 & 1230 & -463.0 & 27.2 \\
3 & 50 & 113.6 & 180.7 & 366.0 & -464.0 & 78.3 \\
4 & $\mathrm{HCl}$ & 100 & 93.50 & 176.2 & 124.0 & -461.0 & 92.7 \\
5 & & 200 & 95.10 & 152.8 & 76.50 & -491.0 & 95.5 \\
6 & 300 & 86.30 & 158.1 & 52.30 & -486.0 & 96.9 \\
7 & & 400 & 89.70 & 154.9 & 38.50 & -475.0 & 97.7 \\
\hline 8 & & $\mathrm{Blank}$ & 215.2 & 375.8 & 2120 & -480.0 & - \\
9 & 10 & 210.0 & 410.8 & 1530 & -467.0 & 27.8 \\
10 & & 50 & 155.3 & 331.9 & 875.0 & -471.0 & 58.7 \\
11 & $\mathrm{H}_{2} \mathrm{SO}_{4}$ & 100 & 141.1 & 326.6 & 603.0 & -468.0 & 71.6 \\
12 & & 200 & 118.3 & 226.2 & 366.0 & -466.0 & 82.7 \\
13 & & 300 & 123.6 & 262.6 & 269.0 & -469.0 & 87.3 \\
14 & & 400 & 130.4 & 267.4 & 193.0 & -479.0 & 90.9 \\
\hline
\end{tabular}


the $\mathrm{E}_{\mathrm{corr}}$ records no significant change in these studies indicating that the inhibitor prevents both the anodic and cathodic reaction by blocking the available active surface by adsorption [45].

\subsection{Potential of zero charge (PZC)}

In both the medium, the blank and the protected samples show more negative $\mathrm{E}_{\mathrm{pzc}}$ than that of $\mathrm{E}_{\mathrm{ocp}}$ as observed from differential capacitance plot (Fig. 7) and reveals that the mild steel surface possess a positive charge and the values are presented in Table 4.

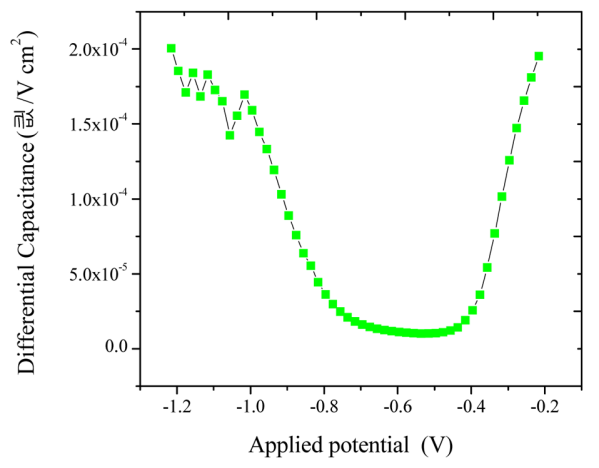

(a)

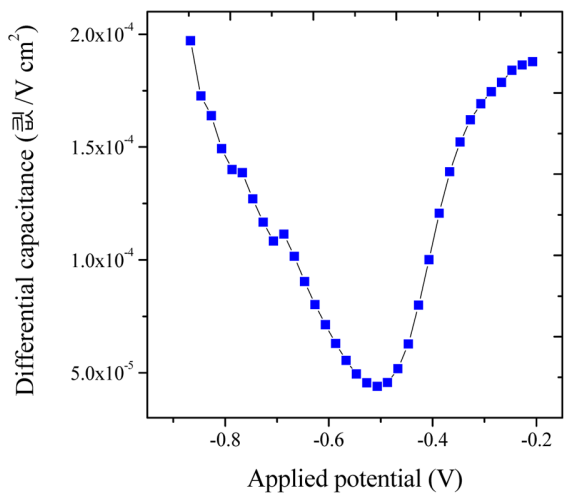

(c)
Based on the surface charge, the mechanism is proposed that the reversible adsorption of the anions $\left(\mathrm{Cl}^{-}\right.$ or $\mathrm{SO}_{4}{ }^{2-}$ ) followed by anodic dissolution involving the release of electrons from the adsorbed anions to the metal surface and desorption of the adsorbed anions along with $\mathrm{Fe}^{2+}$ ions, after picking up electrons from the Fe atoms [45-49]. The mechanistic steps of dissolution of $\mathrm{Fe}$ is presented in the following scheme $[47,48]$. The schiff's base molecules, in the protonated form are in equilibrium with the corresponding molecular (unprotonated) form in both the

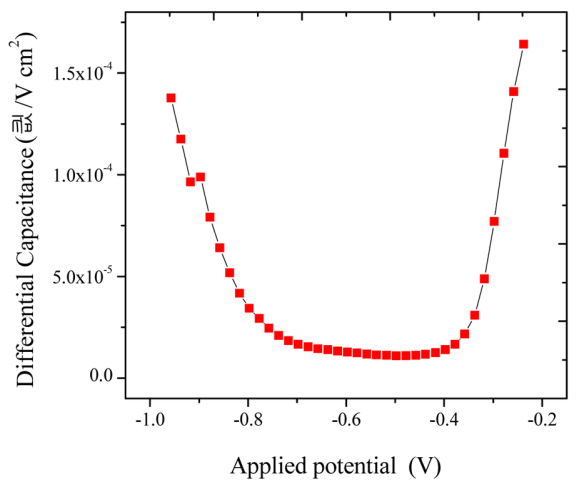

(b)

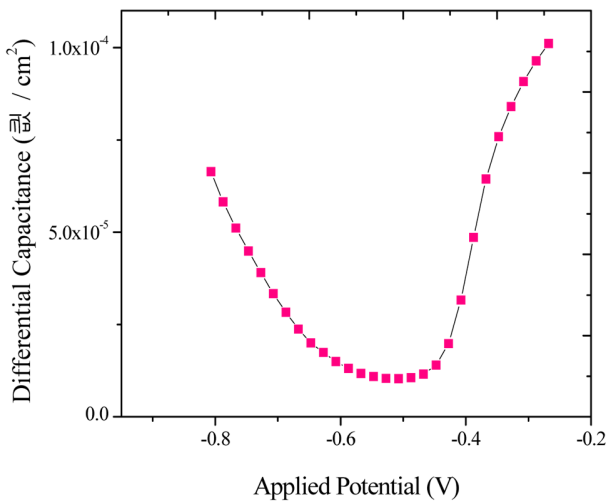

(d)

Fig. 7. The plot of differential capacitance vs. applied DC potential in (a) $1 \mathrm{M} \mathrm{HCl}$ solution (b) $1 \mathrm{M} \mathrm{HCl}$ containing $400 \mathrm{mg} /$ $\mathrm{L}$ of the inhibitor (c) $0.5 \mathrm{M} \mathrm{H}_{2} \mathrm{SO}_{4}$ solution d) $0.5 \mathrm{M} \mathrm{H}_{2} \mathrm{SO}_{4}$ containing $400 \mathrm{mg} / \mathrm{L}$ of the inhibitor solution.

Table 4. Excess charge on mild steel electrode in $1.0 \mathrm{M} \mathrm{HCl}$ and $0.5 \mathrm{M} \mathrm{H}_{2} \mathrm{SO}_{4}$ solutions

\begin{tabular}{cccccc}
\hline \hline S. No & Medium & Concentration & $\mathrm{E}_{\text {ocp }}(\mathrm{mV} / \mathrm{SCE})$ & $\mathrm{E}_{\mathrm{pzc}} \mathrm{mV}(\mathrm{mV} / \mathrm{SCE})$ & Net Charge \\
\hline 1 & $\mathrm{HCl}$ & Blank & -487.0 & -536.0 & $+\mathrm{ve}$ \\
2 & & $400 \mathrm{ppm}$ & -475.0 & -498.0 & $+\mathrm{ve}$ \\
3 & $\mathrm{H}_{2} \mathrm{SO}_{4}$ & Blank & -480.0 & -507.0 & $+\mathrm{v}$ \\
4 & & $400 \mathrm{ppm}$ & -479.0 & -507.0 & $+\mathrm{ve}$ \\
\hline
\end{tabular}


acid solutions. Thus, because of electrostatic repulsion, it is very difficult for the positively charged inhibitor to approach the positively charged metal surface. The anions act as connecting bridges between the positively charged metal surface and the protonated organic inhibitors.

$$
\begin{aligned}
& \mathrm{Fe}+\mathrm{Cl}^{-} / \mathrm{SO}_{4}^{2-} \rightarrow(\mathrm{FeCl})_{\mathrm{ads}} /\left(\mathrm{FeSO}_{4}^{2-}\right)_{\mathrm{ads}} \\
& \left(\mathrm{FeCl}^{-}\right)_{\mathrm{ads}} /\left(\mathrm{FeSO}_{4}^{2-}\right)_{\mathrm{ads}} \\
& \leftrightarrow(\mathrm{FeCl})_{\mathrm{ads}} /\left(\mathrm{FeSO}_{4}\right)_{\mathrm{ads}}+\mathrm{e}^{-} / 2 \mathrm{e}^{-} \\
& (\mathrm{FeCl})_{\mathrm{ads}} /\left(\mathrm{FeSO}_{4}\right)_{\mathrm{ads}} \\
& \leftrightarrow\left(\mathrm{FeCl}^{+}\right)_{\mathrm{ads}} /\left(\mathrm{FeSO}_{4}^{2+}\right)_{\mathrm{ads}}+\mathrm{e}^{-} / 2 \mathrm{e}^{-} \\
& \left(\mathrm{FeCl}^{+}\right)_{\mathrm{ads}} /\left(\mathrm{FeSO}_{4}^{2+}\right)_{\mathrm{ads}} \leftrightarrow \mathrm{Fe}^{2+}+\mathrm{Cl}^{-} / \mathrm{SO}_{4}^{2-}
\end{aligned}
$$

The inhibitor performance of the schiff's base could occur through the following two processes [50].

- Adsorption of the protonated species through electrostatic interaction with the negatively charged surface, which is provided with the specifically adsorbed anion on the metal surface $\left[\left(\mathrm{FeCl}^{-}\right)_{\text {ads }}\right.$ species $]$

- Chemisorption of the unprotonated schiff base molecules, which are in equilibrium with the protonated ones, through the interaction of unshared electron pair on $\mathrm{N}$ atom with the metal surface.

\subsection{IR Spectral studies}

FTIR spectra were recorded to understand the inter-

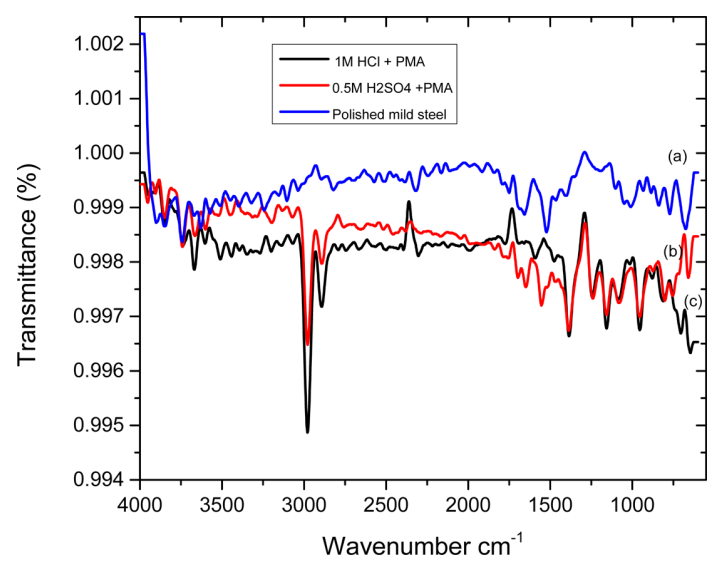

Fig. 8. ATR spectra of (a) Polished mild steel (b) $0.5 \mathrm{M}$ $\mathrm{H}_{2} \mathrm{SO}_{4}$ and $\mathrm{PMA}$ (c) $1 \mathrm{M} \mathrm{HCl}$ and PMA. action of inhibitor molecules with the metal surface. Figs. 8 shows the IR spectra of polished metal surface and the inhibitor adsorbed metal surface taken in attenuated total reflection mode in the acid media. The

(a)
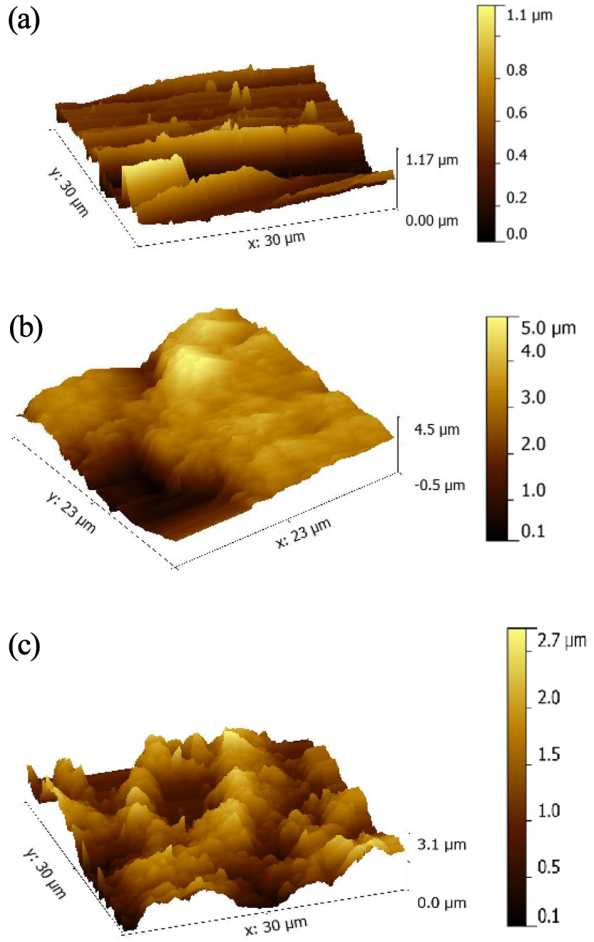

(d)
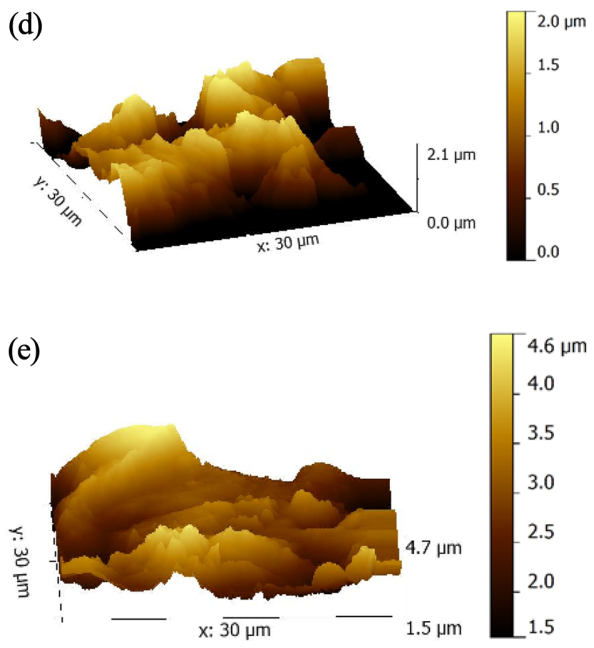

Fig. 9. AFM images of mild steel (a) with Polished surface (b) in $1 \mathrm{M} \mathrm{HCl}$ (c) in $0.5 \mathrm{M} \mathrm{H}_{2} \mathrm{SO}_{4}$ (d) in $1 \mathrm{M} \mathrm{HCl}$ containing 400ppm of PMA (e) in $0.5 \mathrm{M} \mathrm{H}_{2} \mathrm{SO}_{4}$ containing 400ppm of PMA. 
Table 5. AFM data for mild steel surface in different environment

\begin{tabular}{ccc}
\hline \hline S. No & Sample & $\mathrm{Ra}(\mu \mathrm{m})$ \\
\hline 1 & Polished mild steel & 0.14 \\
2 & Mild steel immersed in $1 \mathrm{M} \mathrm{HCl}$ & 0.756 \\
3 & Mild steel immersed in $1 \mathrm{M} \mathrm{HCl}+400 \mathrm{ppm} \mathrm{PMA}$ & 0.559 \\
4 & Mild steel immersed in $0.5 \mathrm{M} \mathrm{H}_{2} \mathrm{SO}_{4}$ & 0.411 \\
5 & Mild steel immersed in $0.5 \mathrm{M} \mathrm{H}_{2} \mathrm{SO}_{4}+400 \mathrm{ppm} \mathrm{PMA}$ & 0.406 \\
\hline
\end{tabular}

attenuated total reflection infrared (ATR IR) spectra of polished metal surface and corroded metal surface in the presence of inhibitor are different. The appearance of many new peaks could be due to the adsorbed inhibitor molecules onto the metal surface.

\subsection{Atomic Force Microscope}

AFM is considered to be a powerful tool to explore the surface morphology at nano to microscale and has become a new choice to discuss the corrosion process at the metal/solution interface. The threedimensional (3D) AFM images of the surface of polished mild steel, those immersed in acid $(1 \mathrm{M} \mathrm{HCl}$ and $0.5 \mathrm{M} \mathrm{H}_{2} \mathrm{SO}_{4}$ ) solutions and in acid solution containing $400 \mathrm{ppm}$ of PMA (1 $\mathrm{M} \mathrm{HCl}+\mathrm{PMA}$ and $0.5 \mathrm{M} \mathrm{H}_{2} \mathrm{SO}_{4}+\mathrm{PMA}$ ) are shown in Fig. 9. The average roughness $(\mathrm{Ra})$ values for the polished mild steel surface, unprotected and protected surfaces are given in Table 5. Lower Ra values for inhibited sample indicates the existence of smoother surface and hence a lower corrosion rate as a result of formation of protective film by adsorption of inhibitor molecules on the surface of mild steel [51,52].

\subsection{Adsorption isotherm}

Inhibition of corrosion of metals by organic inhibitors is a result of their adsorption on the metal surface. Four types of interactions may take place involving organic molecule at the metal solution interface [53]:

i. Electrostatic attraction between charged molecules and charged metal surface

ii. Interaction of unshared electron pairs in the molecules with the metal surface

iii. Interaction of $\pi$ - electron of the inhibitor molecule with the metal surface and

iv. A combination of all the above.

Adsorption isotherms can provide important clues

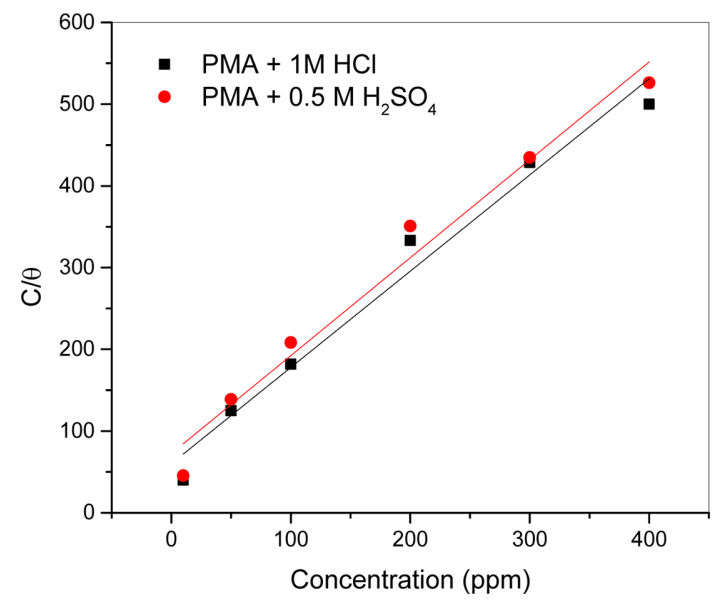

Fig. 10. Langmuir adsorption plots for mild steel in $1 \mathrm{M}$ $\mathrm{HCl}$ and $0.5 \mathrm{M} \mathrm{H}_{2} \mathrm{SO}_{4}$ containing various concentrations of PMA at $30^{\circ} \mathrm{C}$.

on the nature of metal inhibitor interaction and determination of the type of adsorption isotherm is achieved by taking into account the degree of surface coverage $(\theta)$ as a function of inhibitor concentration [54]. The surface coverage values were calculated employing equation (8).

$$
\theta=\left(1-\frac{\mathrm{i}^{\prime}{ }_{\text {corr }}}{\mathrm{i}_{\text {corr }}}\right)=\left(1-\frac{\mathrm{R}_{\mathrm{ct}}}{\mathrm{R}_{\mathrm{ct}}^{\prime}}\right)=\left(1-\frac{\mathrm{CR}_{\mathrm{inh}}}{\mathrm{CR}_{\mathrm{b}}}\right)
$$

where,

$\mathrm{i}_{\text {corr }} \& \mathrm{i}_{\text {corr }}=$ Corrosion current densities of inhibited and uninhibited systems respectively

$\mathrm{R}_{\mathrm{ct}} \& \mathrm{R}_{\mathrm{ct}}^{\prime}=$ Charge transfer resistance at inhibited and uninhibited systems respectively

$\mathrm{CR}_{\text {inh }}=$ Corrosion rate of the metal in inhibited solution

$\mathrm{CR}_{\mathrm{b}}=$ Corrosion rate of the metal in blank solution

The plot of $C / \theta$ against inhibitor concentration $C$ is a straight line (Fig.10). The linear plot with high correlation coefficient $(0.9775$ and 0.9765$)$ clearly reveals 
that the adsorption process obeys the Langmuir isotherm, which could be expressed as follows [55].

$$
\frac{\mathrm{c}}{\theta}=\left(\frac{1}{\mathrm{~K}_{\mathrm{ads}}}\right)+\mathrm{C}
$$

Where, $\mathrm{K}_{\mathrm{ads}}$ is a adsorption equilibrium constant. Free energy of adsorption $\left(\Delta \mathrm{G}_{\mathrm{ads}}\right)$ can be calculated using equation 10 .

$$
\mathrm{K}_{\mathrm{ads}}=\left(\frac{1}{55.5}\right) \exp ^{\left(-\Delta \mathrm{G}_{\mathrm{ads}} / \mathrm{RT}\right)}
$$

The value of $\Delta \mathrm{G}_{\mathrm{ads}}$ for adsorption of PMA in $1 \mathrm{M} \mathrm{HCl}$ and $0.5 \mathrm{M} \mathrm{H}_{2} \mathrm{SO}_{4}$ solution was found to be -25.00 and -24.02 respectively. The negative value of $\Delta \mathrm{G}_{\mathrm{ads}}$ suggests that PMA is spontaneously adsorbed on to the mild steel surface. According to literature, if $\Delta \mathrm{G}_{\mathrm{ads}}$ values are in the range of $-20 \mathrm{~kJ} /$ $\mathrm{mol}$ and $-40 \mathrm{~kJ} / \mathrm{mol}$ represent both physisorption and chemisorption [56] on the metal surface. Thus in the present study on $\mathrm{HCl}$ and $\mathrm{H}_{2} \mathrm{SO}_{4}$ solution the PMA molecules get adsorbed on the metal surface by both physisorption and chemisorption through electrostatic interaction between the anion bridges and the protonated inhibitor and also through direct interaction between the heteroatoms of the inhibitor and the metal surface respectively.

\subsection{Adsorption kinetics}

The corrosion process is a chemical reaction in which the $\mathrm{Fe}$ atoms at the metal surface react with the negatively charged anions $\left(\mathrm{OH}^{-}, \mathrm{Cl}^{-}, \mathrm{SO}_{4}{ }^{2-}\right)$. Temperature has its influence on the interaction between the mild steel surface and the acidic media in the absence and in the presence of inhibitors [57]. To assess the influence of temperature on corrosion and corrosion inhibition processes, the weight loss measurements were carried out at $30-60^{\circ} \mathrm{C}$ temperature range. The results obtained indicate that corrosion rate increase with temperature both in inhibited and uninhibited solutions. The dependence of corrosion rate on the temperature can be regarded as an Arhenius-type process, the rate of which is given by equation 11 [58].

$$
\log C \mathrm{R}=\left(\log \mathrm{A}-\frac{\mathrm{E}_{\mathrm{a}}}{2.303 \mathrm{RT}}\right)
$$

Where,

$\mathrm{CR}=$ corrosion rate, $\mathrm{E}_{\mathrm{a}}=$ Activation energy,

$\mathrm{R}=$ Molar gas constant, $\mathrm{T}=$ Absolute temperature, $\mathrm{A}=$ Frequency factor

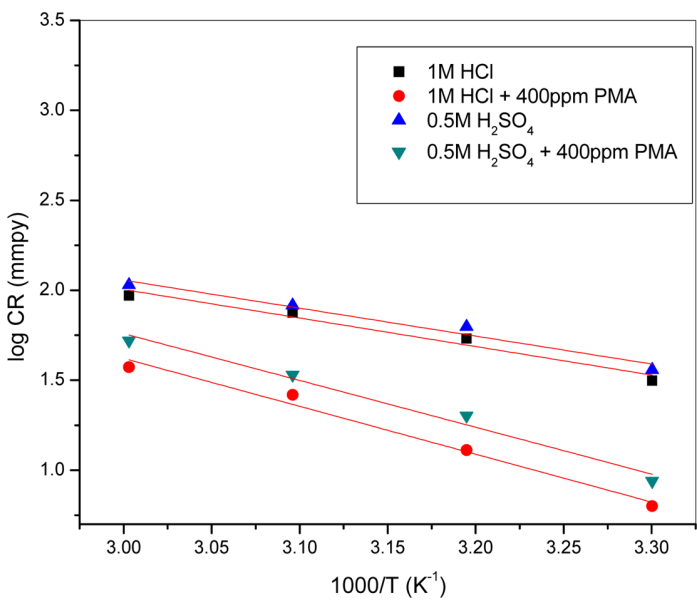

Fig. 11. Arhenius plots for corrosion of mild steel in ( $\mathbf{\square})$ $1 \mathrm{M} \mathrm{HCl}$ solution $(\bullet) 1.0 \mathrm{M} \mathrm{HCl}$ containing $400 \mathrm{mg} / \mathrm{L}$ of the inhibitor, $(\boldsymbol{\Delta}) 0.5 \mathrm{M} \mathrm{H}_{2} \mathrm{SO}_{4}$ solution $(\boldsymbol{\nabla}) 0.5 \mathrm{M} \mathrm{H}_{2} \mathrm{SO}_{4}$ containing $400 \mathrm{mg} / \mathrm{L}$ of the inhibitor.

The Arhenius plots of 1/T against log CR (Fig. 11) were constructed and from the slopes $\mathrm{E}_{\mathrm{a}}$ values were calculated and summarized in Table 6. It is evident that the values of the apparent activation energies for the inhibited solutions are higher than that in the uninhibited solutions indicating that the inhibitor induces an energy barrier for the corrosion reaction leading to the decrease in rate of corrosion [59]. Literature revealed that the higher $\mathrm{E}_{\mathrm{a}}$ value for corrosion process in the presence of the inhibitor is ascribed to its physical nature of adsorption [60].

\subsection{Correlation and comparison of results}

The efficiency of the inhibitor was compared with similar compounds reported and it is found to be better $(97 \%)$ compared with the results reported by $\mathrm{K}$ Jobby Thomas et al (82.8\%) [61], W.Yang et al $(90.8 \%)$ [62] and W.Yang et al (85\%) [63].

\section{Quantum Chemical Studies}

Density Functional Theory is found to be successful in providing insights into the chemical reactivity and selectivity in terms of global parameters, such as electronegativity $(\chi)$, hardness $(\eta)$ softness $(S)$, fraction of electron transferred $(\Delta N)$, chemical potential $(\mu), \mathrm{E}_{\text {Hомо }}, \mathrm{E}_{\mathrm{Lumo}}$ and energy difference between LUMO and HOMO ( $\Delta \mathrm{E})[64]$. By using density 
Table 6. Values of $\mathrm{E}_{\mathrm{a}}$ of PMA adsorbed on mild steel surface at $30^{\circ} \mathrm{C}, 40^{\circ} \mathrm{C}, 50^{\circ} \mathrm{C}$ and $60^{\circ} \mathrm{C}$.

\begin{tabular}{cccccc}
\hline \hline \multirow{2}{*}{ Medium } & Temperature & \multicolumn{2}{c}{ Log CR (mmpy) } & \multicolumn{2}{c}{ Ea } \\
\cline { 3 - 5 } & $1000 / \mathrm{T}\left(\mathrm{K}^{-1}\right)$ & Blank & $400 \mathrm{ppm}$ & Blank & $400 \mathrm{ppm}$ \\
\hline \multirow{3}{*}{$\mathrm{HCl}$} & 3.3 & 1.49 & 0.79 & & \\
& 3.2 & 1.73 & 1.11 & 22.18 & 43.39 \\
& 3.1 & 1.87 & 1.42 & & \\
& 3.0 & 1.97 & 1.57 & & \\
& 3.3 & 1.56 & 0.94 & & \\
$\mathrm{H}_{2} \mathrm{SO}_{4}$ & 3.2 & 1.79 & 1.30 & & \\
& 3.1 & 1.92 & 1.53 & & \\
& 3.0 & 2.03 & 1.72 & & \\
\hline
\end{tabular}

Table 7. Quantum Chemical parameters of PMA

\begin{tabular}{|c|c|c|c|c|c|}
\hline S. No & QC parameters & Neutral & $4 \mathrm{NH}^{+}$ & $14 \mathrm{NH}^{+}$ & $4 \mathrm{NH}^{+} \& 14 \mathrm{NH}^{+}$ \\
\hline 1 & Total energy $(\mathrm{eV})$ & -1980.010 & -1993.737 & -11370.312 & -2007.151 \\
\hline 2 & $\mathrm{E}_{\text {номо }}(\mathrm{eV})$ & -9.254 & -7.708 & -7.236 & -7.102 \\
\hline 3 & $\mathrm{E}_{\text {LUMO }}(\mathrm{eV})$ & -1.081 & -0.046 & -0.335 & -0.05 \\
\hline 4 & $\Delta \mathrm{E}(\mathrm{eV})$ & 8.173 & 7.662 & 6.901 & 7.052 \\
\hline 5 & Ionization potential (I/eV) & 9.254 & 7.708 & 7.236 & 7.102 \\
\hline 6 & Electron affinity $(\mathrm{A} / \mathrm{eV})$ & 1.081 & 0.046 & 0.335 & 0.05 \\
\hline 7 & Hardness ( $\eta / e v)$ & 4.087 & 3.831 & 3.4505 & 3.526 \\
\hline 8 & Softness (S/eV) & 0.122 & 0.130 & 0.145 & 0.142 \\
\hline 9 & Electronegativity $(\chi)$ & 5.1675 & 3.877 & 3.7855 & 3.576 \\
\hline 10 & Electrophilicity $(\omega)$ & 3.267 & 1.962 & 2.077 & 1.813 \\
\hline 11 & $\begin{array}{l}\text { Fraction of electrons trans- } \\
\text { ferred }(\Delta N)\end{array}$ & 0.224 & 0.408 & 0.466 & 0.486 \\
\hline 12 & Chemical Potential & -5.168 & -3.877 & -3.786 & -3.576 \\
\hline 13 & Volume (Cubic Angstroms) & 227.35 & 228.93 & 230.61 & 231.62 \\
\hline
\end{tabular}

functional theory (DFT) theoretical calculations were made in Spartan 08 program package, at B3LYP/6-31 $\mathrm{G}(\mathrm{d}, \mathrm{p})$ level of theory. Optimization of the molecular structure was performed in a water phase [65-67]. Unoccupied d-orbitals of a Fe atom in the neutral form accept the electrons from inhibitor molecule and form a co-ordinate bond (Chemisorption). Simultaneously antibonding orbitals of Fe back donate the electrons to the inhibitor molecule (physisorption) which is in the protonated form [68]. This co-ordination and back donation process strengthens the adsorption of different structures of PMA molecule on the mild steel surface.

The HOMO and LUMO population of the studied
PMA molecule and the corresponding cases of protonated forms are shown in Fig. 12 and the values are presented in Table 7.

Highest $\mathrm{E}_{\text {HOMO }}$ observed in protonated structure denotes that it has greater tendency to donate electrons to mild steel surface [68]. However, Lowest $\mathrm{E}_{\text {LUMO }}$ is observed for neutral form shows its involvement in adsorption process [69]. $\mathrm{E}_{\text {HOMO }}$ and $\mathrm{E}_{\mathrm{LUMO}}$ depict the adsorption of both protonated and neutral form during inhibition.

The important parameter that determines the reactivity of the inhibitor molecule towards its adsorption on to the metallic surface is the energy gap between the HOMO and LUMO of the molecule. For 


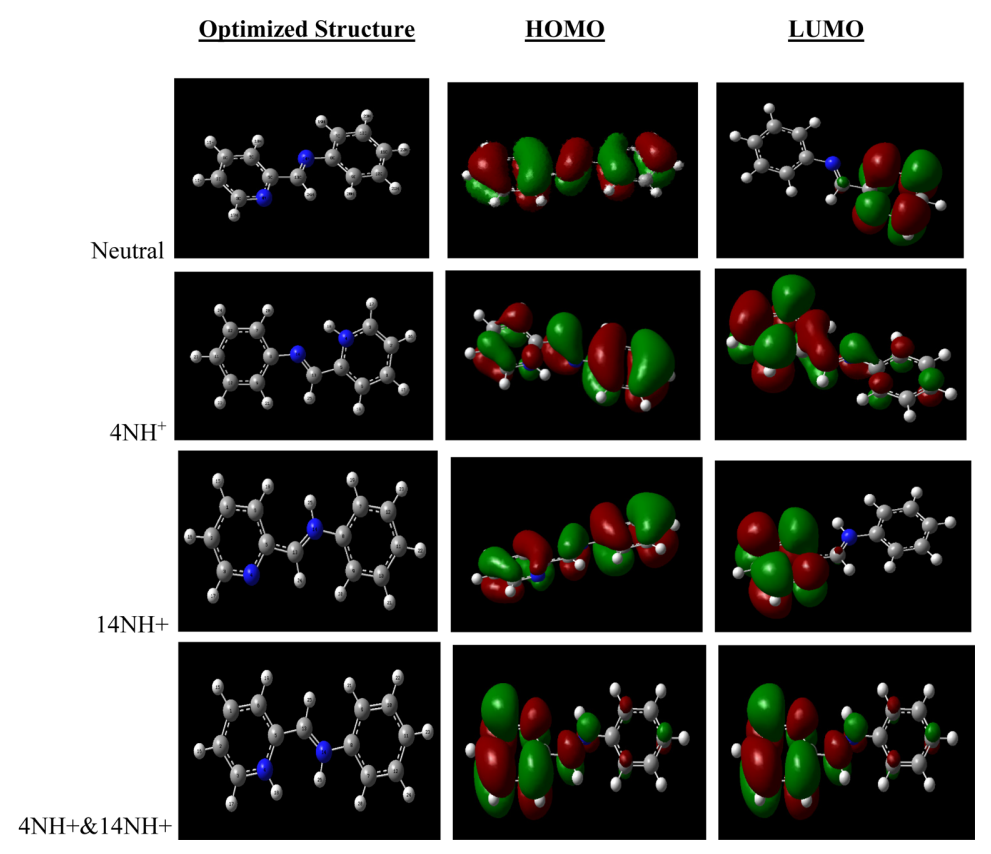

Fig. 12. Optimized molecular structure, HOMO and LUMO molecular orbitals of PMA.

effective overlapping, the energy gap must be low. As $\Delta \mathrm{E}$ decreases, the reactivity of the molecule increases leading to increase in the inhibition efficiency of the molecule [69]. The lower $\Delta \mathrm{E}$ values observed for the protonated structures $(7.662,6.901$ and 7.052) when compared to that of the neutral form of the inhibitor molecule (8.173) reveals that the adsorption occurs predominantly through protonated structures [70,71].

The information on the contact surface between the inhibitor and the metal is given by the molar volume. The inhibition efficiency is usually proportional to the fraction of the surface covered by the adsorbed inhibitor [72]. The protonated structure of PMA has the highest molar volume than the neutral form which provides the largest coverage area and the highest inhibition efficiency.

The fraction of electrons transferred to the metal from the inhibitor is another vital factor. In general, the inhibitor efficiency increases with increase in electron donating ability of the metal surface provided the $\Delta \mathrm{N}$ should be less than $3.6[73,74]$. Hence, the fraction of electrons transferred $(\Delta N)$ from the Schiff base to the metal is calculated from following equation 12 and presented in Table 11 $[67,70]$.

$$
\Delta N=\left(\chi_{M}-\chi_{l}\right) / 2\left(\eta_{M}+\eta_{I}\right)
$$

In the present study, protonated form of PMA has a higher $\Delta \mathrm{N}$ and hence shows better inhibition.

The hardness and softness are also very important to measure the molecular reactivity. Molecule with low hardness and high softness value can be expected to have highest inhibition efficiency $[75,76]$. Protonated form of PMA has low hardness and high softness values. Hence it adsorbs more easily than the neutral form.

From the above results, it is clear that both physisorption and chemisorption are possible and also it is noted that physisorption dominates. The results are in accordance with the observed $\Delta \mathrm{G}_{\text {ads }}$ values $(-25.00$ and -24.02 for $\mathrm{HCl}$ and $\mathrm{H}_{2} \mathrm{SO}_{4}$ respectively).

To find the protonation place on the inhibitor, Mulliken population analysis was carried out. It is clear from Table 8 that in the protonated structure, electron density is accumulated more on nitrogen atom. Hence in acidic solution, the nitrogen can get protonated easily and electrostatically adsorb on to the metal surface via anion bridge [77]. This is in accordance with the $\Delta \mathrm{G}^{\mathrm{o}}$ values calculated from the Langmuir adsorption isotherm and physisorption dominates over chemisorption. 
Table 8. Mulliken Charge distribution of PMA

\begin{tabular}{ccccccccc}
\hline \hline \multirow{2}{*}{ S. No } & \multicolumn{2}{c}{ Neutral form } & \multicolumn{2}{c}{$\begin{array}{c}\text { Protonation at } \\
\text { amine Nitrogen }\end{array}$} & \multicolumn{2}{c}{$\begin{array}{c}\text { Protonation at Pyridine } \\
\text { ring Nitrogen }\end{array}$} & \multicolumn{2}{c}{$\begin{array}{c}\text { Protonation at both Pyridine } \\
\text { ring and amine Nitrogen }\end{array}$} \\
\cline { 2 - 8 } & Atom type & charge & Atom type & charge & Atom type & charge & Atom type & charge \\
\hline 1 & $\mathrm{C}$ & -0.150494 & $\mathrm{C}$ & -0.127653 & $\mathrm{C}$ & -0.111200 & $\mathrm{C}$ & -0.092806 \\
2 & $\mathrm{C}$ & 0.225128 & $\mathrm{C}$ & -0.198195 & $\mathrm{C}$ & -0.235129 & $\mathrm{C}$ & -0.210021 \\
3 & $\mathrm{C}$ & 0.058381 & $\mathrm{C}$ & 0.076137 & $\mathrm{C}$ & 0.184862 & $\mathrm{C}$ & 0.209930 \\
4 & $\mathrm{~N}$ & -0.582201 & $\mathrm{~N}$ & -0.549858 & $\mathrm{~N}$ & -0.824512 & $\mathrm{~N}$ & -0.842967 \\
5 & $\mathrm{C}$ & 0.146075 & $\mathrm{C}$ & 0.166923 & $\mathrm{C}$ & 0.352329 & $\mathrm{C}$ & 0.337058 \\
6 & $\mathrm{C}$ & -0.131950 & $\mathrm{C}$ & -0.145217 & $\mathrm{C}$ & -0.173503 & $\mathrm{C}$ & -0.146901 \\
7 & $\mathrm{C}$ & -0.152892 & $\mathrm{C}$ & -0.175721 & $\mathrm{C}$ & -0.131629 & $\mathrm{C}$ & -0.157207 \\
8 & $\mathrm{C}$ & 0.289928 & $\mathrm{C}$ & 0.400149 & $\mathrm{C}$ & 0.281640 & $\mathrm{C}$ & 0.404904 \\
9 & $\mathrm{C}$ & -0.184746 & $\mathrm{C}$ & -0.180114 & $\mathrm{C}$ & -0.172775 & $\mathrm{C}$ & -0.167901 \\
10 & $\mathrm{C}$ & -0.198408 & $\mathrm{C}$ & -0.176148 & $\mathrm{C}$ & -0.187488 & $\mathrm{C}$ & -0.161315 \\
11 & $\mathrm{C}$ & -0.181133 & $\mathrm{C}$ & -0.162009 & $\mathrm{C}$ & -0.159258 & $\mathrm{C}$ & -0.136788 \\
12 & $\mathrm{C}$ & -0.188772 & $\mathrm{C}$ & -0.169740 & $\mathrm{C}$ & -0.180147 & $\mathrm{C}$ & -0.157850 \\
13 & $\mathrm{C}$ & 0.179742 & $\mathrm{C}$ & 0.303883 & $\mathrm{C}$ & 0.173593 & $\mathrm{C}$ & 0.300072 \\
14 & $\mathrm{~N}$ & -0.678821 & $\mathrm{~N}$ & -0.912087 & $\mathrm{~N}$ & -0.671541 & $\mathrm{~N}$ & -0.896453 \\
\hline
\end{tabular}

\section{Conclusions}

The effectiveness of the newly synthesised schiff base PMA as an inhibitor for the corrosion of mild steel in $1 \mathrm{M} \mathrm{HCl}$ and $0.5 \mathrm{M} \mathrm{H}_{2} \mathrm{SO}_{4}$ solutions was studied by using weight loss, electrochemical and quantum chemical methods. The following are the conclusions drawn:

- The schiff base is a good inhibitor for mild steel in both the media.

- Protection efficiency has increased with increase in inhibitor concentration and a 400ppm dose was observed to be an optimum concentration.

- The results of EIS showed that the increase in $\mathrm{R}_{\mathrm{ct}}$ and decrease in $\mathrm{C}_{\mathrm{dl}}$ with inhibitor concentration is due to the increase in the thickness of the electrical double layer and a decrease in local dielectric constant respectively.

- Tafel curves indicate that the inhibitor acts as a mixed type

- Inhibition is achieved by the adsorption of the molecules on to the mild steel surface which follows

- Langmuir isotherm. The calculated value of $\Delta \mathrm{G}$ indicates that the adsorption is spontaneous as well as physical in nature.

- Surface charge determination shows that the sur- face of the mild steel is positively charged in these media. The $\mathrm{Cl}^{-}$and $\mathrm{SO}_{4}{ }^{2-}$ act as connecting bridge between the positively charged metal surface and the protonated inhibitor molecule.

- The efficiency of the inhibitor obtained from weight loss method, electrochemical methods and Quantum chemical calculations are in good agreement.

\section{References}

[1] S. Belkaid, K. Tebbji, A. Mansri, A. Chetouani, B. Hammouti, Res Chem Intermed. 2012, 38(9), 23092325.

[2] Y. X. Li,Y. Y. Zhang, S. Jungwirth, N. Seely, Y. D. Fang, X. M. Shi, Corros. Rev, 2014, 32(5-6), 163-181.

[3] Yujie Qiang, Lei Guo, Shengtao Zhang, Wenpo Li, Shanshan Yu, Jianhong Tan, Sci. Rep, 2016, 6, 33305 (1-14).

[4] D. Daoud, T. Douadi, S. Issaadi, S. Chafaa, Corros. Sci, 2014, 79, 50-58

[5] Quiong Deng, Na-Na Ding, Xiao-Li wei, Liang cai, Xiao-Peng He, Yi-Tao Long, Guo-Rong Chen, Kaixian chen, Corros. Sci, 2012, 64, 64-73.

[6] Quiong Deng, Hong-Wei Shi, Na-Na Ding, Bao-Qin Chen, Xiao-Peng He, Guixia Liu, Yun Tang, Yi- Tao Long, Guo-Rong Chen, Corros. Sci, 2012, 57, 220-227.

[7] Ahmed A. Al-Amiery, Fatin A. Binti Kassim, Abdul Amir H. Kadhum, Abu Bakar Mohamad, Sci. Rep, 2016, 
6, $19890(1-13)$.

[8] V. S. Sastry, Corrosion Inhibitors, Principles and Applications, John Wiley \& Sons, New York, 1998.

[9] F. Bentiss, M. Lagrence, M. Traisnel, Corros, 2000, 56(7), 733-742.

[10] F. Bentiss, M. Traisnel, M. Lagrence, J. Appl. Electrochem, 2001, 31, 41-48.

[11] M. R. Laamari, J. Benzakour, F. Berrekhis, A. Derja, D. Villemin, Arabian. J. Chem, 2016, 9, S245-S251.

[12] M. Lebrini, M. Traisnel, M. Lagrenee, B. Mernari, F. Bentiss, Corros. Sci, 2008, 50(2), 473-479.

[13] B. B. Damaskin, A. N. Frumkin, Adsorption of molecules on electrodes in: N. S. Hush (Ed.), Reaction of molecules at electrodes, Wiley-Interscience, London, 1971.

[14] M. G. Hosseini, M. Ehteshamzadeh, T. Shahrabi, Electrochim. Acta, 2007, 52(11), 3680-3685.

[15] A. Aytaç, Ü. Özmen, M. Kabasakaloğlu, Mater. Chem. Phys, 2005, 89-(1), 176-181.

[16] K. C. Emregül, O. Atakol, Mater. Chem. Phys, 2004, 83(2-3), 373-379.

[17] R.A. Prabhu, T.V. Venkatesha, A.V. Shanbhag, G.M. Kulkarni, R.G. Kalkhambkar, Corros. Sci, 2008, 50(12), 3356-3362.

[18] L. M. Rodríguez-Valdez, A. Martínez-Villafane, D. Glossman-Mitnik, J. Mol. Struct. THEOCHEM, 2004, 681(1-3), 83-88.

[19] Gökhan Gece, Corros. Sci, 2008, 50(11), 2981-2992.

[20] M. Kumaravel, S. Rameshkuamar, S. S. Subramanian, S. Gowri, N. Rajasekaran, A. Selvaraj, Electrochim. Actam, 2011, 56(11), 3857-3863.

[21] A. M. Eldesoky, Hala.M.Hassan, A. S. Fouda, Int. J. Electrochem. Sci, 2013, 8, 10376 - 10395.

[22] A. Doner, R. Solmaz, M. Ozcan, G. Kardas, Corr. Sci, 2011, 53(9), 2902-2913.

[23] E. A. Martins, M. C. L. Oliveira, J. L. Rossi, I. Costa and H. G. de Melo, J. Braz. Chem. Soc, 2011, 22(2), 264-271.

[24] M. Sahin, S. Bilgic, H. Yilmaz, Appl. Surf. Sci, 2002, 195(1-4), 1-7.

[25] A. Popova, E. Sokolova, S. Raicheva, M. Christov, Corros. Sci, 2003, 45(1), 33-58.

[26] A. K. Singh, M. A. Quraishi, Corros. Sci, 2010, 52(4), 1373-1385.

[27] S. K. Shukla, M. A. Quraishi, Corros. Sci, 2010, 52(2), 314-321.

[28] R. S. Chaudhary, S. Sharma, Indian J. Chem. Technol, 1999, 16, 202-206.

[29] C. Verma, L. O. Olasunkanmi, E. E. Ebenso, M. A. Quraishi, and I. B. Obot, J. Phys. Chem. C, 2016, 120(21), 11598-11611.

[30] Z. A. Foroulis, Proc. 6th European Symposium on corrosion Inhibitors, Ann. Univ. Ferrara, Italy, N.S., sez. V, Suppl. N. 8, 1985.

[31] Z. A. Iofa, G. N. Tomashov, Zh. Fiz. Khim, 1960, 34(5), 1036-1043.
[32] T. Murakawa, N. Hackerman, Corros. Sci, 1964, 4(1-4), 387-396.

[33] K. F. Khaled, Int. J. Electrochem. Sci, 2008, 3(4), 462 475.

[34] L. Larabi, Y. Harek, M. Traisnel, A. Mansri, J. Appl. Electrochem, 2004, 34(8), 833-839.

[35] J. R. Macdonald, W. B. Johanson, J. R. Macdonald (Ed.), Theory in Impedance Spectroscopy, John Wiley\& Sons, New York, 1987.

[36] C H. Hsu, F. Mansfeld, Corrosion, 2001, 57(9), 747748.

[37] P. Bommersbach, C. Alemany-Dumont, J. P. Millet, B. Normand, Electrochim. Acta, 2005, 51(6), 1076-1084.

[38] M. S. Abdel-AAl, M. S. Morad, Brit. Corros. J, 2001, 36(4), 253-260.

[39] A. V. Benedeti, P. T. A. Sumodjo, K. Nobe, P. L. Cabot, W. G. Proud, Electrochim. Acta, 1995, 40(16), 26572668.

[40] H. H. Hassan, Electrochim. Acta, 2007, 53(4), 17221730.

[41] M. Hosseini, S. F. L. Mertens, M. Ghorbani, M. R. Arshadi, Mater. Chem. Phys, 2003, 78(3), 800-808.

[42] A. Zarrouk1, H. Zarrok, R. Salghi, R. Touir, B. Hammouti, N. Benchat, L. L. Afrine, H. Hannache, M. El Hezzat, M. Bouachrine, J. Chem. Pharm. Res, 2013, 5(12), 1482-1491.

[43] R. Yildı, T. Dogan, I. Dehri, Corros. Sci, 2014, 85, 215-221.

[44] K. B. Kabir, I. Mahmud, J. Chem. Eng, 2010, 13-17.

[45] A. Hamdy, Nour Sh.El-Gendy, Egypt. J. Pet, 2013, 22(1), 17-25.

[46] R. Solmaz, G. Kardas, M. Culha, B. Yazici, M. Erbil, Electrochim. Acta, 2008, 53, 5941-5952.

[47] M. Morad, J. Morvan, J. Pagetti, In: Proceedings of the 8th European Symposium on Corrosion Inhibitors (8SEIC), Sez. V (Suppl. 10). Ann. Univ. Ferrara, NS, 1995.

[48] K. Aramaki, M. Hagiwara, H. Nishihara, Corros. Sci, 1987, 27(5), 487- 497.

[49] R. Solmaz, M. E. Mert, G. Kardas, B. Yazici, M. Erbil, Acta Phys. Chem. Sinica, 2008, 24(7), 1185-1191.

[50] I. Ahamad, R. Prasad, M. A. Quraishi, Corros. Sci, 2010, 52(4), 1472- 1481.

[51] S. Kumar, H. Vashisht, L. O. Olasunkanmi, I. Bahadur, H. Verma1, G. Singh, Ime. B. Obot, Eno E. Ebenso, Sci. Rep, 2016, 6, 30937 (1-18).

[52] Robert P. Taylor, Proc. ASME. 1989, 79139.

[53] H. Shokry, M. Yuasa, I. Sekine, R. M. Issa, H. Y. ElBaradie, G. K. Gomma, Corros. Sci, 1998, 40(12), 21732186.

[54] A. Yurt, B. Duran, H. Dal, Arabian J. Chem, 2014, 7(5), $732-740$.

[55] O. L. Riggs, R. M. Hurd, R.M., Corros, 1967, 23(8), 252-260.

[56] M. Behpour, S. M. Ghoreishi, A. Gandomi-Niasar, N. Soltani, M. Salavati-Niasari, J. Mater. Sci, 2009, 44(10), 
2444-2453.

[57] Y. Abboud, A. Abourriche, T. Saffaj, M. Berrada, M. Charrouf, A. Bennamara, A. Cherqaoui, D. Takky, Appl. Surf. Sci, 2006, 252(23), 8178-8184.

[58] S. A. R. Ali Fathima, S. Subhashini, Arabian J. Chem. 2017, 10, Supplement 2, S 3358- S 3366.

[59] A. R. S. Priya, V. S. Muralidharam, A. Subramania, Corros, 2008, 64(6), 541-552.

[60] L. Labrabi, Y. Harek, O. Benali, S. Ghalem, Prog. Org. Coatings, 2005, 54(3), 256-262.

[61] C Sini Varghese, K Joby Thomas, Vinod P Raphael and K.S Shaju, Chem Sci Rev Lett, 2017, 6(24), 2300-2308.

[62] Y. Ji , B. Xu , W. Gong, X. Zhang, X. Jin, W. Ning, Y Meng, W. Yang, Y. Chen, J. Taiwan Inst. Chem. E., 2016, 1-12.

[63] B Xu, Y. Ji, X. Zhang, X. Jin, W. Yang, Y. Chen, RSC $A d v$, 2015, 5(69), 56049-56059.

[64] O. Sikemi, O. A. Kolawole, S. Banjo, Manila Journal of Science, 2017, 10(2017), 44-63.

[65] X. Li, S. Deng, T. Lin, X. Xie and G. Du, Corros. Sci, 2017, 118, 202-216.

[66] B. Idir and F. Kellou-Kerkouche, J. Electrochem. Sci. Technol, 2018, 9(4), 260-275.

[67] P. Leena, N. H. Zeinul Hukuman, A. R. Biju, and M.
Jisha, J. Electrochem. Sci. Technol, 2019, 10(2), 231243.

[68] K. R. Ansari, M. A. Quraishi, Ambrish Singh, Measurement, 2015, 76, 136-147.

[69] L. Herrag, B. Hammouti, S. Elkadiri, A. Aouniti, C. Jama, H. Vezin, F. Bentiss, Corros. Sci, 2010, 52(9), 3042-3051.

[70] S. Rameshkumar, I. Danaee, M. RashvandAvei, M. Vijayan, J. Mol. Liq, 2015, 212, 168-186.

[71] P. E. Kumar, M. Govindaraju, V. Sivakumar, AntiCorros Method M, 2018, 65(1), 19-33.

[72] P. R. Roberge, Handbook of Corrosion Engineering, McGraw-Hill, New York, 2000.

[73] V. S. Sastri, J. R. Perumareddi, Corros, 1997, 53(8), 617-622.

[74] I. Lukovits, E. Kalman, F. Zucchi, Corros, 2000, 57, 38.

[75] R. Hasanov, M. Sadiko?lu, S. Bilgiç, Appl. Surf. Sci, 2007, 253(8), 3913-3921.

[76] E. E. Ebenso, D. A. Isabirye, N. O. Eddy, Int. J. Mol. Sci, 2010, 11(6), 2473-2498.

[77] A. Y. Musa, A. H. Kadhum, A. B. Mohamad, A. A. B. Rahoma, H. Mesmari, J. Mol. Struct, 2010, 969(1-3), 233-237. 